\title{
ÇANAKKALE BOĞAZI AKINTI TÜRBİN MODELLENMESİ
}

Öz: Bu çalışmada, Çanakkale boğaz akıntısının akıntı gücü ölçülerek türbin tasarlanmış ve bu türbinin uygulama sahasındaki denemeleri yapılarak uygunluğu test edilmiştir. Ayrıca boğaz akıntısının verimliliği konusunda çalışma yapılmıştır. Akıntının yoğun olduğu ve türbin kurulması açısından uygun olabilecek üç farklı bölge belirlenmiş̧ir. Çalışmada $5 \mathrm{~kW}$ gücündeki türbin boğazda belirlenen bu bölgelere yerleştirilmiş ve farklı akıntı hızlarında türbinin enerji verimliliği ölçülmüştür. Ayrıca akıntı yönünün değişimi ölçülmüş, bu değişimin türbin üzerindeki olumsuz etkileri incelenmiştir.

Anahtar Kelimeler: Akıntı Türbini, Çanakkale Boğazı, Alternatif Enerji, Yenilenebilir Enerji

\section{Modeling of Electricity Production From Canakkale Strait Currents}

\begin{abstract}
In this study, the Canakkale strait discharge turbine designed by measuring the discharge power and conformity tested by experiments on the application field of this turbine. In addition, studies have been conducted on the efficiency of the strait discharge. Three different zones have been identified where the flow is dense and may be suitable for turbine installation. In the study, the turbine at $5 \mathrm{~kW}$ of power was placed in these zones identified in the strait and the energy efficiency of the turbine was measured in different current velocities. Furthermore, the change in the current direction was measured the negative effects of this change on the turbine have been examined.
\end{abstract}

Keywords: Current Turbine, Canakkale Strait, Alternative Energy, Renewable Energy

\section{GíRIş}

Ülkeler enerji gereksinimlerini ağırlıklı olarak fosil yakıtlardan karşılamaktadır. Ancak fosil yakıtların zaman içinde tükenecek olması ve bu yakıtların çevreye verdiği zararlardan dolayı enerjinin kolaylaştırdığı hayatları zehirlemesi, ülkelerin bu yakıtlardan uzaklaşmalarına ve alternatif enerji kaynaklarına yönelmelerine sebep olmaktadır. Elektrik üretiminde alternatif kaynaklar arayışında rüzgârdan, Güneş'ten, deniz akıntılarından ve dalgalarından faydalanmak ilk sıralarda yer almaktadır. Ülkeler her ay ürettikleri alternatif enerji miktarlarıyla dünya gündemine gelmektedirler. Alternatif enerjiden yararlanma ülkelere göre farklilıklar göstermektedir. Bazı ülkeler güneş açısından avantajlı iken diğer ülkelerde rüzgâr açısından

\footnotetext{
${ }^{*}$ Çanakkale Onsekiz Mart Üniversitesi, Çan Meslek Yüksekokulu, Elektrik ve Enerji Bölümü,17400, Çanakkale.
} 
avantajlıdır. Örneğin denize kıyısı olan ülkeler ise deniz akıntıları ve dalgalardan enerji üretmek konusunda avantajlıdır. Bunun için yoğun olarak Ar-Ge çalışmaları yapmaktadırlar. Türkiye'de iki büyük deniz iki uzun boğaz ile birleşmektedir. Bu boğazlarda meydana gelen akıntılardan enerji üretmek mümkündür. Burada sürekli ve çift yönlü bir akıntı vardır. Akıntının başlıca sebebi; boğazın iki uç kısmındaki yoğunluk farkından kaynaklanan ve yoğunluk dengesinin oluşması için gerçekleşen akıntı olmasıdır. Yoğunlukların aynı olmaması farklı deniz seviyesi yükselti değerleri meydana getirir. Oluşan akıntı ile elektrik üretimi gerçekleştirilebilir. Yapılan ölçümlerde Çanakkale Boğazında bazı yerlerdeki akıntı hızı 2,5 m/s kadar çıkmaktadır. Yapılan denemelerde bu akıntı hızlarında verimli sayılabilecek elektrik üretilebileceği gösterilmiştir.

\section{BOĞAZAKINTISI ENERJI POTANSIYYELI}

Su akıntı türbinleri ile rüzgâr türbinlerinin yapıları ve kontrol sistemleri birbirine benzerlik gösterir. Grogan ve diğ.(2013) yapmış oldukları çalışmalarında aynı büyüklükteki rüzgâr ve akıntı türbini karşılaştırıldığında Denklem (1) de hesaplandığı gibi, su türbini rüzgâra göre 800 kat daha fazla enerji taşımaktadır. Su akıntı türbinlerinde sürekli akıntı bulunduğundan rüzgâra göre enerji çıkışı kesiksizdir. Havanın yoğunluğu $1,225 \mathrm{~kg} \cdot \mathrm{m}^{-3}$ ve suyun yoğunluğu $1025 \mathrm{~kg} . \mathrm{m}^{-}$ ${ }^{3}$ olarak alınırsa,

$$
\frac{P_{\text {rüzgar }}}{P_{\text {suakkin }}}=\frac{\frac{1}{2} \rho_{\text {hava }} A U^{3}}{\frac{1}{2} \rho_{\text {su }} A U^{3}}=\frac{\rho_{\text {hava }}}{\rho_{\text {su }}}=\frac{1.225}{1025} \cong \frac{1}{800}
$$

sonucu elde edilir.

Türbin üzerine gelen akıntı, rotorundaki kanatlarda kaldırma kuvveti uygular, kanatlar rotor milinde tork meydana getirir ve eksensel akıntı indüksiyon hareketini oluşturur. Grogan ve diğ.(2013) yaptığı çalışmada eksensel indüksiyon hareketini Denklem (2)'deki gibi ifade etmişlerdir. Burada rotor bir disk olarak kabul edilmiş ve bu diskin dönme hızı $U_{d}$, gelen akıntının hızı $U_{\infty}$ ve disk eksensel indüksiyon faktörü $a$ ile gösterilmiştir. Bu durum akıntı içinde kalan diskin dönme faktörü olarak aşağıdaki gibi tanımlanabilir.

$$
U_{d}=U_{\infty}(1-a)
$$

Grogan ve diğ.(2013) yaptıkları çalışmada eksensel indüksiyon faktörüne ek olarak teğetsel akıntı indüksiyon faktörü de tanımlamıştır. Kanatlar dairesel hareket yaptığından dolayı kanatlardaki teğetsel hız $v_{b}$ açısal hız $\omega$ ile kanat boyu $r$ arasındaki bağıntı Denklem (3)' de ifade edilmiştir. Akıntının kanatlar üzerindeki indiksiyon faktörü $a^{\prime}$ ile ifade edilirse Denklem (4) ifadesinde net teğetsel akıntı hızı $v_{t}$ bulunmuş olur.

$$
\begin{gathered}
v_{b}=\omega \cdot r \\
v_{t}=\left(1+a^{\prime}\right) v_{b}
\end{gathered}
$$

Aşağıdaki Şekil 1'de bir kanada etki eden kuvvetlerin yönleri gösterilmiştir. Burada göreli hız W Denklem (5)'te gösterildiği gibi bağlı olduğu parametreler dik üçgen kuralından bulunur. 


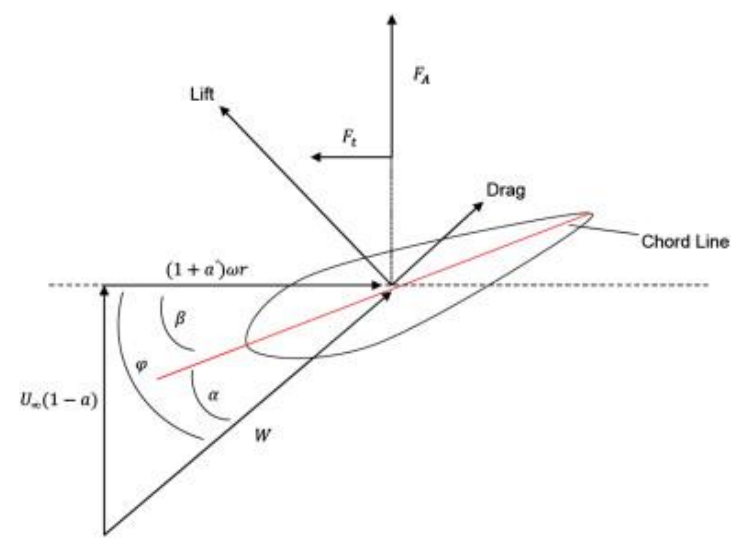

Şekil 1:

Türbin kanatlarına uygulanan kuvvetlerin vektörel pozisyonu Grogan ve diğ.(2013)

$$
W=\sqrt{u_{d}^{2}+v_{t}^{2}}
$$

Türbin kanatlarında gelen akıntı gücü iki kuvvet meydana getirir. Bu kuvvetler kaldırma ve sürüklenme kuvvetleridir. Öncelikle bu kuvvetleri belirleyen itme $C_{D}$ ve kaldırma katsayılarının $\mathrm{C}_{\mathrm{L}}$ bulunmas1 gereklidir. Bu itme $\delta_{D}$ ve kaldırma $\delta_{L}$ kuvvetleri Denklem (6) ve Denklem (7)' de gösterilmiştir (Grogan ve diğ. 2013).

$$
\begin{gathered}
\delta_{L}=\frac{1}{2} \rho w^{2} C_{L} \delta_{r} \\
\delta_{D}=\frac{1}{2} \rho w^{2} C_{D} \delta_{r}
\end{gathered}
$$

Aşağıdaki ifadelerde türbinin ana milinde döndürme meydana getiren kuvvete neden olan, eksenel kuvvet ve kanatların oluşturduğu teğetsel kuvveti verilmektedir (Grogan ve diğ.2013;

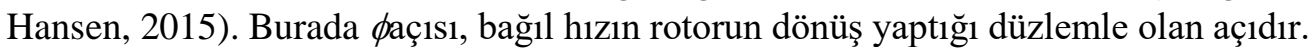

$$
\begin{gathered}
F_{A}=\delta_{L} \cos \phi+\delta_{D} \sin \phi \\
F_{T}=\delta_{L} \sin \phi-\delta_{D} \cos \phi
\end{gathered}
$$



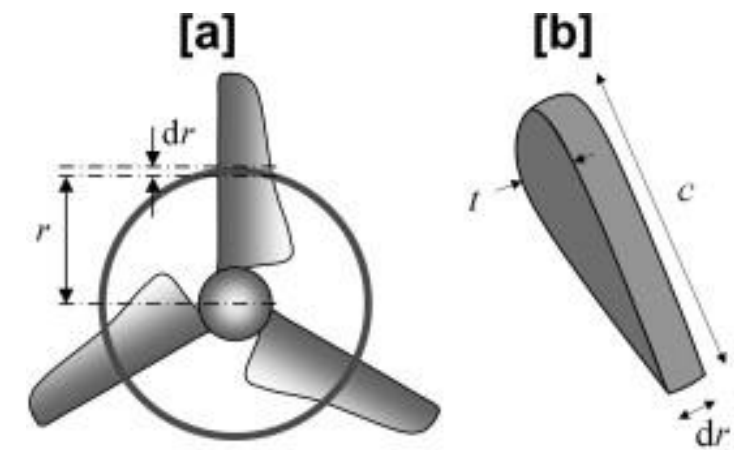

[c]

Şekil 2:

Akıntı türbin kanadına etki eden kuvvetler a): 3 kanatlı türbin rotor bağlantısı b): kanat kesiti c): kanada etki eden kuvvetler (Malki ve diğ.2013).

Akıntı türbinlerinde türbinin kurulum alanı, düzenli akıntının bulunduğu ve ideal derinlikte bulunmalıdır. Tabana yerleştirilen türbinlerde, taban yüzeyinin düz olması ve akıntı içerisinde türbülans yapmaması gerekir. Denklem (10) da açıklık katsayısının türbinlerin kurulum yeri ile alakalı belirleyici bir özelliği vardır. Türbin kurulu olduğu konumu yüzeyden derinliği $H$ ve kanat boyu $L$ oranı açıklık katsayısını $\left(C_{h}\right)$ verir (Birjandi ve diğ. 2013).

$$
C_{h}=\frac{H}{L}
$$

Akıntıya yerleştirilen türbinler birbirlerine en az zarar verecek konumda yerleştirilir. Yerleştiren her bir türbin akıntı hızında ve akıntının yön değişiminde etkisi olur. Bu yüzden kurulan türbinler için tıkanıklık katsayısı Denklem (11) ifadesi ile belirlenir. Bu ifade türbin kanatlarının taradığı alan $A$ ile akış kesit alanı $A_{c}$ arasındaki oranıdır (Birjandi ve diğ. 2013).

$$
B=\frac{A}{A_{c}}
$$

Türbinlerdeki enerji aktarımına bakıldığında gelen akıntı hızı türbin kanatlarına çarpar, kanatlardan geçtikten sonra hızı düşerek dümen suyunu oluşturarak yoluna devam eder. Bu durumda gelen akıntı ile kuyruk suyu arasındaki enerji farklılığı türbinin verimini $C_{p}$ ifadesini belirler. Denklem(12) de kanatlar üzerindeki akışkanın hızı $V_{t}$ kanatlara ulaşmadan yeteri kadar uzaklıktaki akıntı hızı $U$ oranı Denklem (13) ile $\beta$ değişkenini verir. Denklem (14) deki $\tau$ değeri kanatlara etkisi olmadan geçen (bypass) akıntı hızının kanatlardan önceki akıntının hızına oranıdır. Denklem (15) de bulunan $\varepsilon$ değerini, kanatlardan sonraki çıkış dümen suyunun gelen akıntı hızına oranıdır. Denklem (16) ifadesinde $\Delta_{h}$ ifadesi akıntı yüzeyi ile türbin kurulduğu derinlik değerini, $h$ ise akışkanın aktığı kanal derinliğini gösterir (Birjandi ve diğ. 2013).

$$
\begin{gathered}
C_{p}=\beta\left(\tau^{2}-\varepsilon^{2}\right) \\
\beta=\frac{V_{t}}{U}
\end{gathered}
$$




$$
\begin{gathered}
T=\frac{V_{b}}{U} \\
\varepsilon=\frac{V_{\omega}}{U} \\
\beta=\frac{\varepsilon}{B(\tau-\varepsilon)}\left[\tau\left(1-\frac{h}{h}\right)-1\right]
\end{gathered}
$$

Akışkanın hareketinin incelenmesinde Froude Katsayısı $F_{r}$ belirleyici bir değerdir. Denklem (17) ifadesinde Froude Katsayısı ile türbin derinliği akıntı hızları arasındaki ilişki gösterilmiştir (Birjandi ve diğ. 2013).

$$
\frac{\Delta_{h}}{h}=\frac{F_{r}^{2}}{2}\left(\tau^{2}-1\right)
$$

Potansiyel enerjiye sahip olan akışkanın harekete geçmesi kinetik enerji taşımasına sebep olur. Taşınan bu birinci formdaki enerjiyi ikinci formdaki mekanik hareket enerjisine dönüşmesinde kurallar vardır. Akışkan ve kütleye sahip olan bir sıvının akması bir enerji taşıdığ 1 ve bu enerji de kinetik (hareket) enerji formülü ile ifade edilebilir. Kinetik enerji ifadesinde bulunan kütlenin yerine kütlesel debi $\left(\dot{m}=\frac{d m}{d t}=\rho A U\right)$ yazılırsa akışkanın taşıdığ enerji miktarı ve güç bulunur (Çengel ve Cimbala. 2010).

$$
\begin{aligned}
& E_{k}=\frac{1}{2} \dot{m} U^{2} \\
& P_{\text {gü̧ }}=\frac{1}{2} \rho A U^{3}
\end{aligned}
$$

Tasarlanan Şekil 3'teki iki kanatlı türbin, Çanakkale Boğazının farklı bölgelerinde 0 - 2,4 $\mathrm{m} / \mathrm{s}$ akıntı hızlarında denenmiştir. Akıntının özellikle yön değiştirdiği yerlerde küçük kanatlı türbinlerin tasarlanan diğer 3 kanatlı $(48 \mathrm{~cm}$ kanat uzunluğu) türbine göre daha az yön değiştirdiği izlenmiştir. 


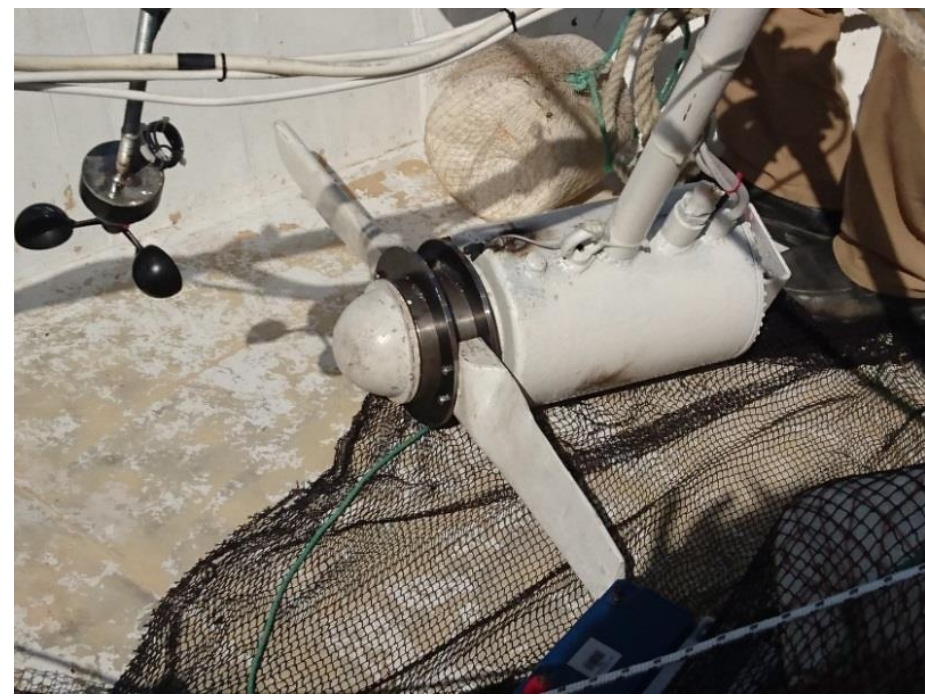

Şekil 3:

İki kanatlı $38 \mathrm{~cm}$ kanat boyuna sahip olan türbinin rotor bağlantısı

\subsection{Güç Katsayısı}

Akıntı türbinlerinde türbine etki eden parametreler türbinin verimini ifade eder. Bu değer ne kadar yüksek ise akıntıdan gelen enerjiyi dönüştürme oranı da o kadar yüksektir. Verim değeri lineer momentum teorisine göre, Betz Limitini $\left(C_{P} \leq 0,59\right)$ aşamaz (Şenel ve Koç 2014). Denklem (20) ifadesinde gösterildiği gibi güç katsayısı $\left(C_{P}\right)$, türbin ana mil devri yanında kanatların akıntı yönüne yunuslama (pitch) açısı, gelen akışkanın kanatlara uygulamış olduğu tork kuvveti, kanatların taradığı alanın yarıçapına ve kanat uç hız oranına bağlıdır (Bal ve diğ. 2015).

$$
C_{P}=\frac{16 n T}{\pi \rho U^{3} r^{2}}
$$

Türbinler kanatları ile düzlemsel hareketi dairesel harekete dönüştürür. Dairesel hareketin gücünü ise tork kuvveti belirler. Türbin şaftında oluşan tork kuvveti alternatörün hareketini sağlar. Tork kuvveti kanatların verimini belirler. Denklem (21) ifadesinde tork kuvvetinin açısal hız ile ters orantılı olduğu görülmektedir. Türbinlerde kanat uzunlukları artarsa açısal hız azalır ve tork artar (Cui ve di ğ. 2012).

$$
Q=\frac{P}{\omega}=\frac{1}{2} \frac{\rho A U^{3} C_{P}}{\omega}
$$

Kanatların alternatör şaftında oluşturduğu tork değerini bulabilmek için Cui ve diğ. (2012) yapmış olduğu çalışmada aşağıdaki ifadeyi kullanmışlardır.

$$
C_{P}=(0,44-0,0167 \beta) \sin \frac{2,5 \pi(\lambda-3)}{15-0,3 \beta}
$$

Denklem (22) deki güç hesaplamasında, $\beta$ kanat açısı ve $\lambda$ kanat uç hız oranıdır. Akıntı türbinlerinde, türbin özelliklerini belirleyici özelliklerinden biride Denklem (23) deki kanat uç hız oranıdır. Bu oran Denklem (23) te kanatların yapmış olduğu açısal hızın $\omega$ 
gelen akıntı hızına $U$ olan oranıdır. $\lambda$ değeri kanat boyu ile de orantılıdır (Jing ve diğ. 2017).

$$
\lambda=\frac{\omega}{U} r
$$

Kanat tasarımında verimi belirleyen iki parametre vardır. $C_{P}$ güç ve $C_{T}$ itme katsayıları Denklem (24) ve (25) ifadesinde gösterildiği gibi gelen akıntı hızının kanat boyu ve akıntının taşıdığı enerji miktarı $P$ ve itme $T$ değeri ile orantılı olarak değişmektedir. Burada $C_{P}$ güç katsayısı değeri gelen akıntının elektrik enerjisine dönüştüğü oran olarak adlandırılabilir (Jing ve diğ. 2017).

$$
\begin{gathered}
C_{P}=\frac{P}{\frac{1}{2}\left(\frac{\rho U^{3} \pi r^{2}}{4}\right)} \\
C_{T}=\frac{T}{\frac{1}{2}\left(\frac{\rho U^{3} \pi r^{2}}{4}\right)}
\end{gathered}
$$

\section{3. ÇALIŞMA DÜZENEĞ́̇}

Tasarlanan türbin, Çanakkale Boğazında akıntının farklı özellikler gösterdiği, üç farklı bölgede denendi. $\mathrm{Bu}$ türbin için kanat uzunlukları $38 \mathrm{~cm}$ ve $48 \mathrm{~cm}$ olan 2 farklı kanat tipi denemeleri yapıldı. $38 \mathrm{~cm}$ olan kanatlar rotora Şekil 3'te gösterildiği gibi iki adet bağlandı. $48 \mathrm{~cm}$ olan kanatlar ise rotora üç kanatlı olarak Şekil 4'de gösterildiği gibi bağlandı.

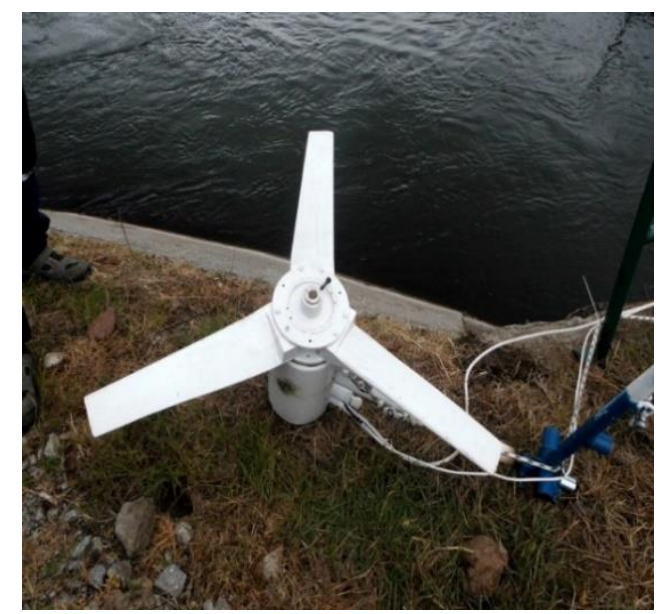

Şekil 4:

3 kanatlı (kanat boyu $48 \mathrm{~cm}$ ) türbinin deneme çalışmaları

Yapılan denemelerin sonucu akıntı hızına bağlı olarak güç değişimi ile akıntı yönünün değişimine göre türbinin davranışları incelendi. Şekil 5'de iki kanatlı türbin rotorun bağlantı bölümü ve türbin kanat kesitinin (kanat profili) kısımları gösterilmiştir. 


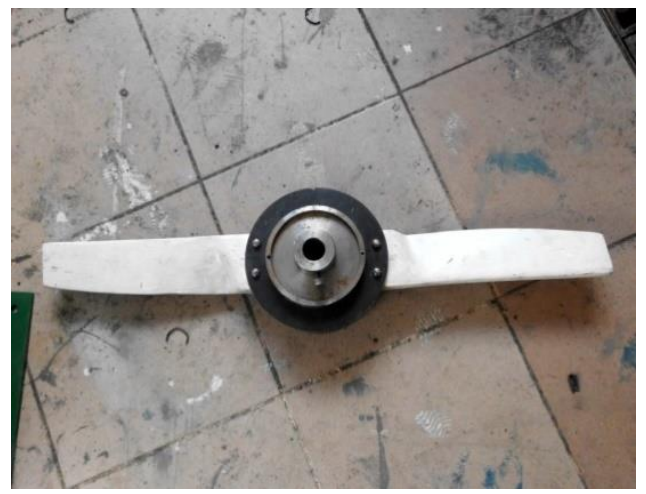

Şekil 5:

Kanat kesitindeki değişkenlerin adlarının gösterimi

Tablo1.Tasarlanan kanadın ölçüleri kant boyu $2 \mathrm{~cm}$ aralıklarla bölünmüş bu bölmelere karşılık gelen kalınlık, veter uzunlukları, açı değişimi, değerleri gösterilmektedir $(10 \mathrm{~cm}$ hub bağlantı).

\begin{tabular}{|c|c|c|c|c|c|c|c|c|c|}
\hline \multicolumn{5}{|c|}{$\mathrm{r}=32 \mathrm{~cm}$ kanat boyu ölçüleri } & \multicolumn{5}{|c|}{$\mathrm{r}=48 \mathrm{~cm}$ kanat boyu ölçüleri } \\
\hline $\begin{array}{c}\text { kanat } \\
\text { boyu } \\
{\left[\mathbf{r}_{\mathrm{i}}\right]} \\
(\mathrm{cm})\end{array}$ & $\begin{array}{c}\text { (kalunlık) } \\
{[\mathrm{t}](\mathbf{c m})}\end{array}$ & $\begin{array}{c}\text { (veter } \\
\text { uzunluğu) } \\
{[\mathbf{c}](\mathbf{c m})}\end{array}$ & $\begin{array}{c}\text { açı } \\
\text { değişimi } \\
\text { (pitch) }\end{array}$ & $\mathbf{r}_{\mathrm{i}} / \mathbf{r}$ & $\begin{array}{c}\text { kanat } \\
\text { boyu } \\
{[\mathbf{r}](\mathbf{c m})}\end{array}$ & $\begin{array}{c}\text { (kalınlık) } \\
{[\mathrm{t}](\mathrm{cm})}\end{array}$ & $\begin{array}{c}\text { (veter } \\
\text { uzunluğu) } \\
{[\mathrm{c}](\mathrm{cm})}\end{array}$ & $\begin{array}{c}\text { açı } \\
\text { değişimi } \\
\text { (pitch) }\end{array}$ & $\mathbf{r}_{\mathrm{i}} / \mathbf{r}$ \\
\hline 4 & 3,9 & 8,1 & 22,000 & 0,125 & 4 & 5 & 11,9 & 22,000 & 0,083 \\
\hline 6 & 3,733 & 7,958 & 20,715 & 0,188 & 6 & 4,873 & 11,746 & 21,182 & 0,125 \\
\hline 8 & 3,566 & 7,816 & 19,430 & 0,250 & 8 & 4,746 & 11,592 & 20,364 & 0,167 \\
\hline 10 & 3,399 & 7,674 & 18,145 & 0,313 & 10 & 4,619 & 11,438 & 19,546 & 0,208 \\
\hline 12 & 3,232 & 7,532 & 16,860 & 0,375 & 12 & 4,492 & 11,284 & 18,728 & 0,250 \\
\hline 14 & 3,065 & 7,39 & 15,575 & 0,438 & 14 & 4,365 & 11,13 & 17,910 & 0,292 \\
\hline 16 & 2,898 & 7,248 & 14,290 & 0,500 & 16 & 4,238 & 10,976 & 17,092 & 0,333 \\
\hline 18 & 2,731 & 7,106 & 13,005 & 0,563 & 18 & 4,111 & 10,822 & 16,274 & 0,375 \\
\hline 20 & 2,564 & 6,964 & 11,720 & 0,625 & 20 & 3,984 & 10,668 & 15,456 & 0,417 \\
\hline 22 & 2,397 & 6,822 & 10,435 & 0,688 & 22 & 3,857 & 10,514 & 14,638 & 0,458 \\
\hline 24 & 2,23 & 6,68 & 9,150 & 0,750 & 24 & 3,73 & 10,36 & 13,820 & 0,500 \\
\hline 26 & 2,063 & 6,538 & 7,865 & 0,813 & 26 & 3,603 & 10,206 & 13,002 & 0,542 \\
\hline 28 & 1,896 & 6,396 & 6,580 & 0,875 & 28 & 3,476 & 10,052 & 12,184 & 0,583 \\
\hline 30 & 1,729 & 6,254 & 5,295 & 0,938 & 30 & 3,349 & 9,898 & 11,366 & 0,625 \\
\hline 32 & 1,562 & 6,112 & 4,010 & 1,000 & 32 & 3,222 & 9,744 & 10,548 & 0,667 \\
\hline & & & & & 34 & 3,095 & 9,59 & 9,730 & 0,708 \\
\hline & & & & & 36 & 2,968 & 9,436 & 8,912 & 0,750 \\
\hline & & & & & 38 & 2,841 & 9,282 & 8,094 & 0,792 \\
\hline & & & & & 40 & 2,714 & 9,128 & 7,276 & 0,833 \\
\hline & & & & & 42 & 2,587 & 8,974 & 6,458 & 0,875 \\
\hline & & & & & 44 & 2,46 & 8,82 & 5,640 & 0,917 \\
\hline & & & & & 46 & 2,333 & 8,666 & 4,822 & 0,958 \\
\hline & & & & & 48 & 2,206 & 8,512 & 4,004 & 1,000 \\
\hline
\end{tabular}




\section{TEST ANALIZ VE SONUÇLARIN KARŞILAŞTIRILMASI}

\subsection{Birinci Uygulama Yeri (Kilitbahir kalesi önü)}

Birinci uygulama yerinde yapılan ölçümlerde Şekil 6'daki akıntı hızı değişim grafiğindeki gösterimde, akıntı 2,25-2,55 m/s değerleri arasında olduğu görüldü. Ölçüm yapılan saha kıyıya uzaklığı yaklaşık $30 \mathrm{~m}$ ve derinlik ise ortalama $17 \mathrm{~m}$ olarak ölçüldü. Bu bölge akıntı hızının ortalama $2,30 \mathrm{~m} / \mathrm{s}$ ile Çanakkale Boğazının en verimli olduğu yerlerden biridir. Akıntı hız değişiminin boğazın diğer yerlerindeki ölçümlere göre daha düzenli olduğu da gözlemlendi. Akıntı hız değişiminin sebepleri arasında deniz yüzeyi üzerindeki rüzgâr kaynaklı dalgalanmalarında etkisi olduğu görülmüştür. Havanın nispeten rüzgârın az olduğu zamanlarda dalgalanmanın az olduğu, bunun sonucu olarak da akıntı daha düzenli olduğu gözlemlendi.

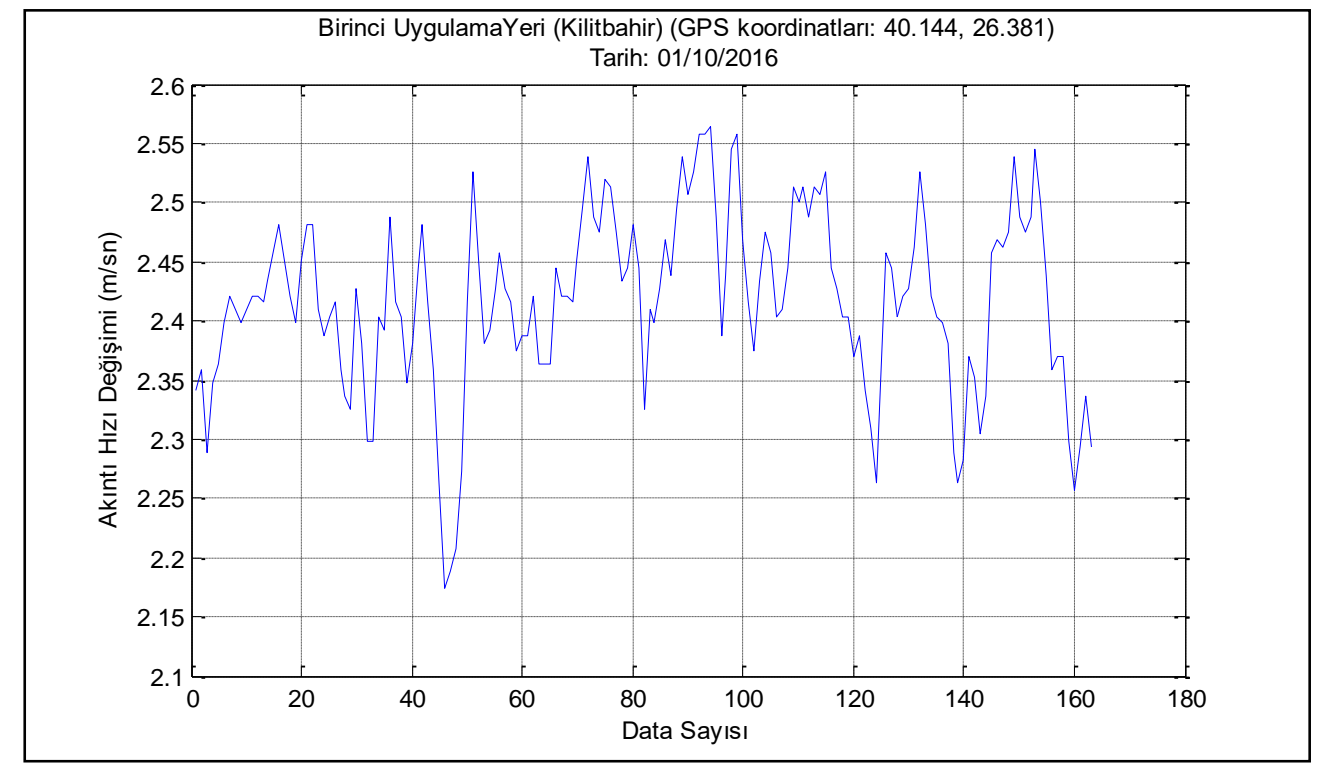

\section{Şekil 6:}

Birinci uygulama yeri (Kilitbahir) akıntı hızı değişimi

Uygulamalarda Şekil 7 de verilen akıntı yönün değişimi 0-360 derece arasında değer verebilen elektronik pusula ile ölçüm yapıldı. Türbin değişen akıntı yönüne göre, kanatlar dik olacak şekilde otomatik olarak yönelmiştir. Yapılan ölçümlerde akıntı yönün değişimi ortalama $40^{\circ}$ olduğu hesaplanmıştır. Bu değer özellikle akıntı yönün çok değişmediği deniz akıntılarında, gemi geçişlerinden kaynaklandığı görülmüştür. Gemi geçişinin olmadığı durumlarda akıntı yönü ortalama $10^{\circ}$ değişim göstermiştir. Özellikle Boğazdaki gemi trafiği sürekli ve yoğun olduğundan akıntı yönündeki etkisi de fazladır. $\mathrm{Bu} 10^{\circ}$ lik yön değişimi türbindeki kule yön değişimi (yaw) sisteminin kontrolünün yapıldığında türbini enerji çıkışını çok etkilemediği görülmüştür. $10^{\circ}$ 'nin üzerindeki akıntı yön değişimlerinde yaw motorlarının sürekli aktif olduğu görülmüştür. Bu durum enerji çıkış verimliliğini de etkilemiştir. Eğer yaw kontrolü yapılmaz ise enerji verimliliğinin düştüğü gözlemlenmiştir. Çanakkale Boğazın da akıntının olduğu yerlerin geneline bakıldığında buradaki akıntı yönü değişimi, en az olan bölgesidir. 


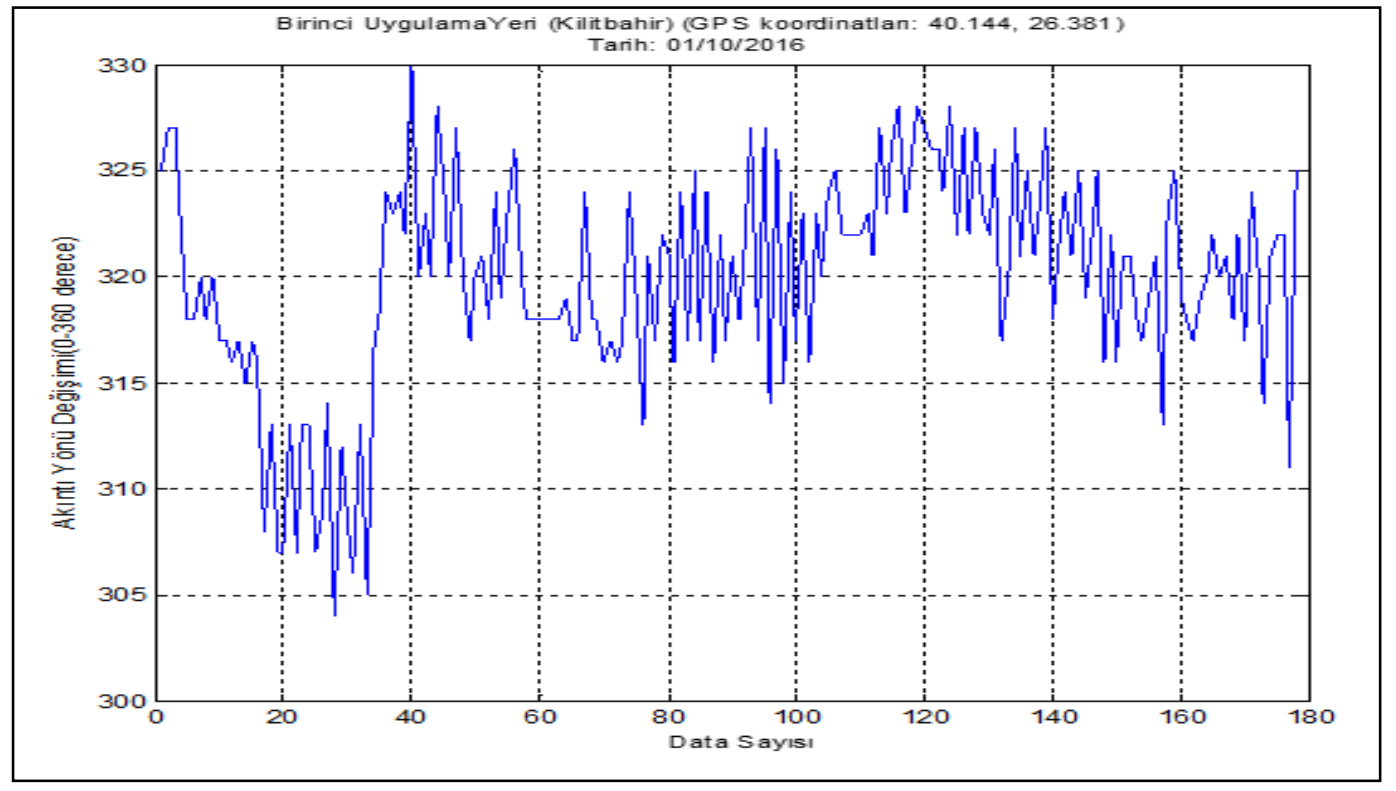

Şekil 7:

Birinci uygulama yeri (Kilitbahir) akıntı yönü değişimi

Eğer türbin devir sayısı sabit tutulursa verimli enerji elde edilir. Burada akıntı hızının değişimi türbin devrini etkilemektedir. Türbin devir üzerindeki etkileri Şekil 8'e baktığımızda, akıntı hızının 2,2-2,5 m/s değerleri arasındaki hızlarda olduğu bulunmuştur. Akıntı hızı değiştiğinde, türbin kanat açılarını değiştirerek devrini sabit tutmaya çalışmıştır. Ayrıca şebekeye paralel çalışan regüle devresi olduğundan kirli elektrik aktarılması önlenmiştir.

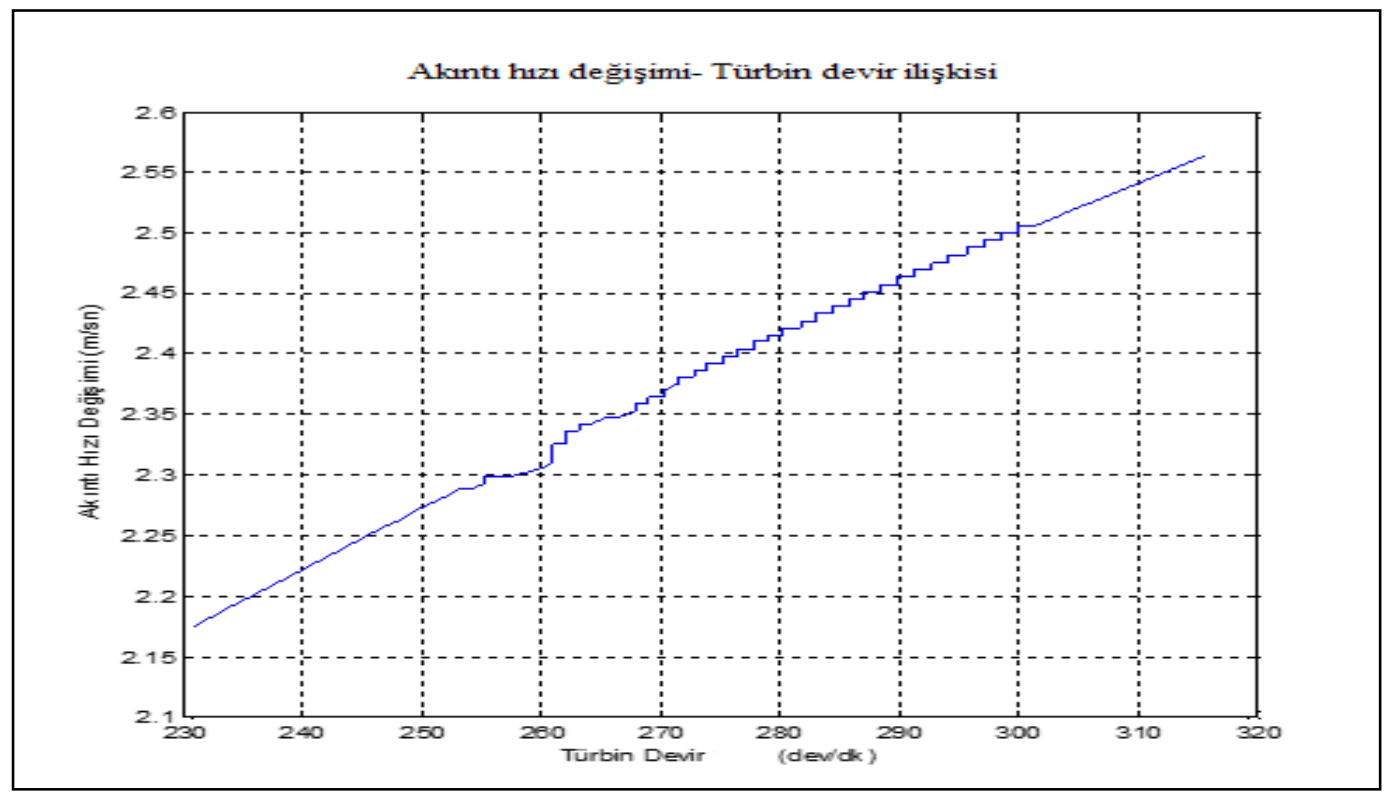

Sekil 8:

Akıntı hızı-Türbin devir ilişsisi 


\section{2 İkinci Uygulama Yeri (Tabyalar)}

Akıntı hızının ve yönün değiştiği farklı yerlerde türbin denemeleri yapılmıştır. Şekil 9' da ise GPS koordinatları verilen ( 40,141;26,379) ikinci uygulama sahasını gösterilmektedir. Saha akıntı yön değişimin yaşandığı bölgede olduğundan türbülanslı akıș bulunmaktadır. Burada yatay eksenli türbin ile yapılan uygulama çalışmasında türbin kulesinin çok fazla hareket ettiği gözlemlenmiştir.

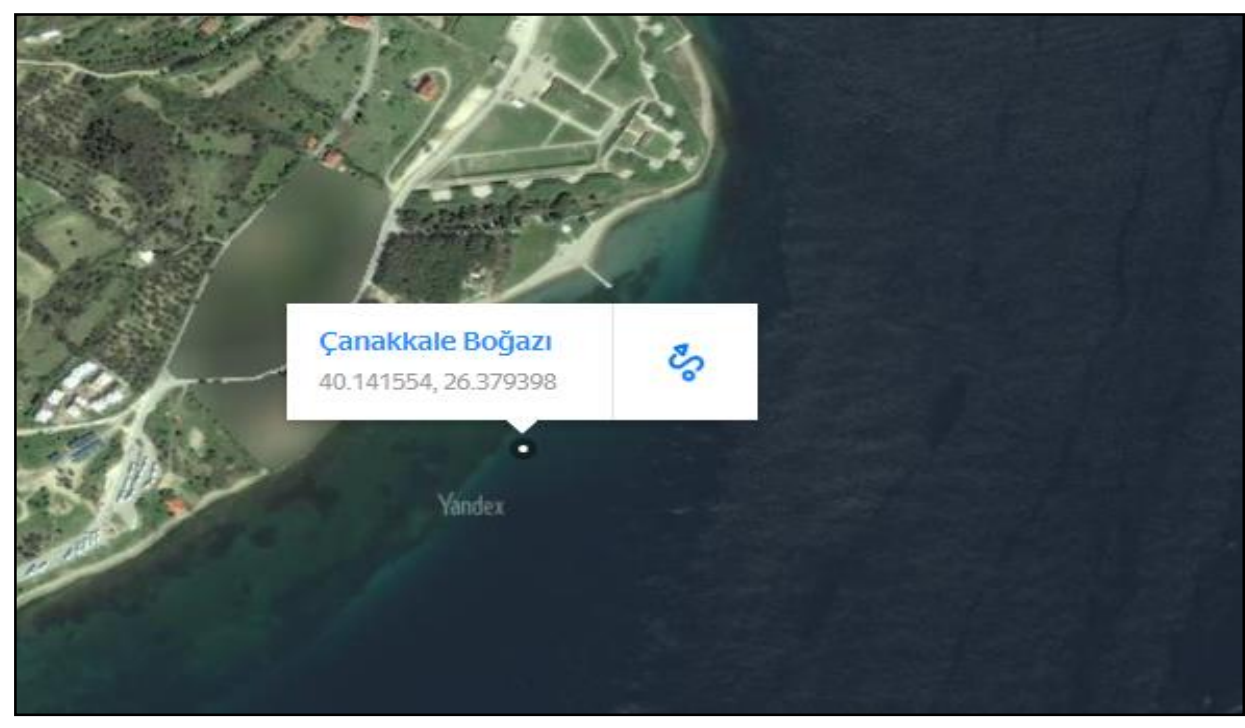

Şekil 9:

İkinci uygulama sahası coğrafi konumu ve GPS koordinatları gösterimi

Şekil 10da akıntı hızı değişimi verilen bu bölge 0,4-1,44 m/s aralığında hıza sahiptir. Buradaki akıntı hızının değişimi boğazdaki gemi geçişlerinin etkilerinden daha çok bölgenin coğrafi konum olarak sivri bir burun bölgesinin arkasında kalmasından dolayıdır.

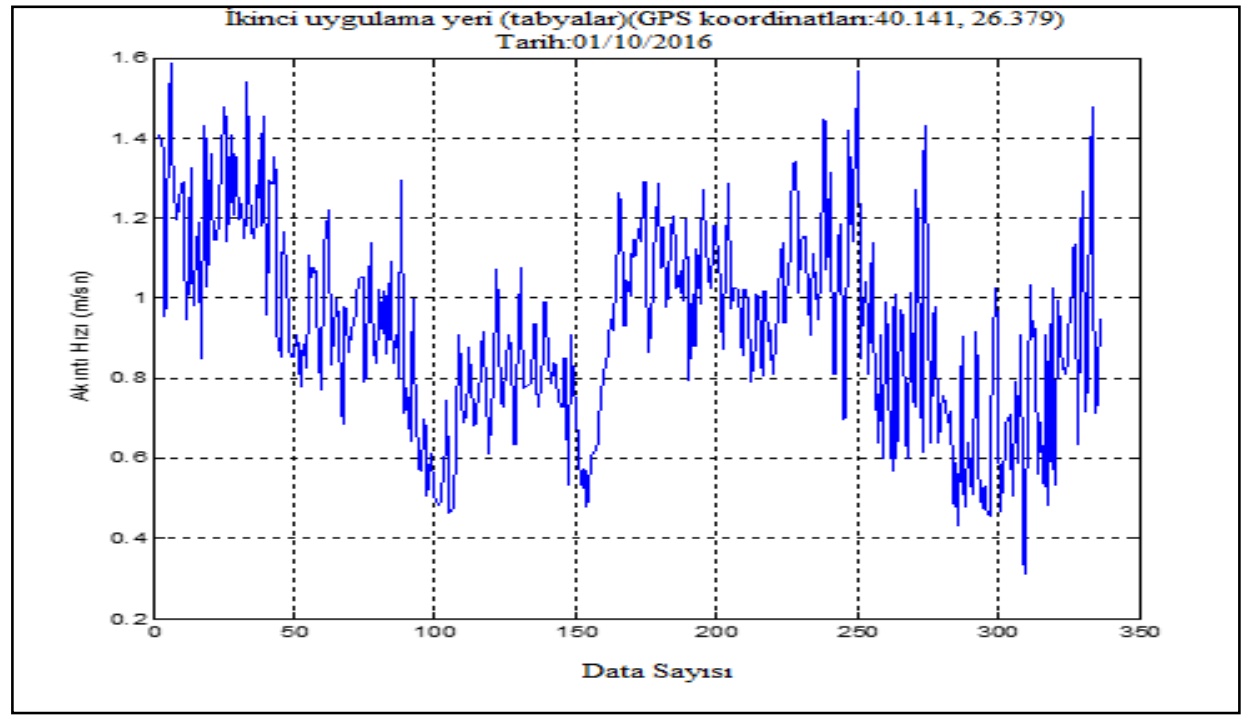

Sekil 10:

Uygulama alanı ikideki akıntı hızı değişimi grafiği 
İkinci uygulama alanındaki akıntı yön değişimi Şekil 11'de verilen akıntı yön değişimi grafiğginde, $60^{\circ}$ lik bir akıntı yön değişimi bulunmuştur. Akıntının sürekli yön değisştiği bölgelerde yatay eksenli türbinlerin akıntıya dik yönelmesi yaw motorlarının sürekli aktif olmasını gerektirir. Sürekli aktif olması enerji kaybı ve zamanla motorların arızalanmasına sebep olacaktır. Bu şekildeki akıntı olan bölgelere dikey eksenli türbinlerin yerleştirilmesi uygun görülmektedir.

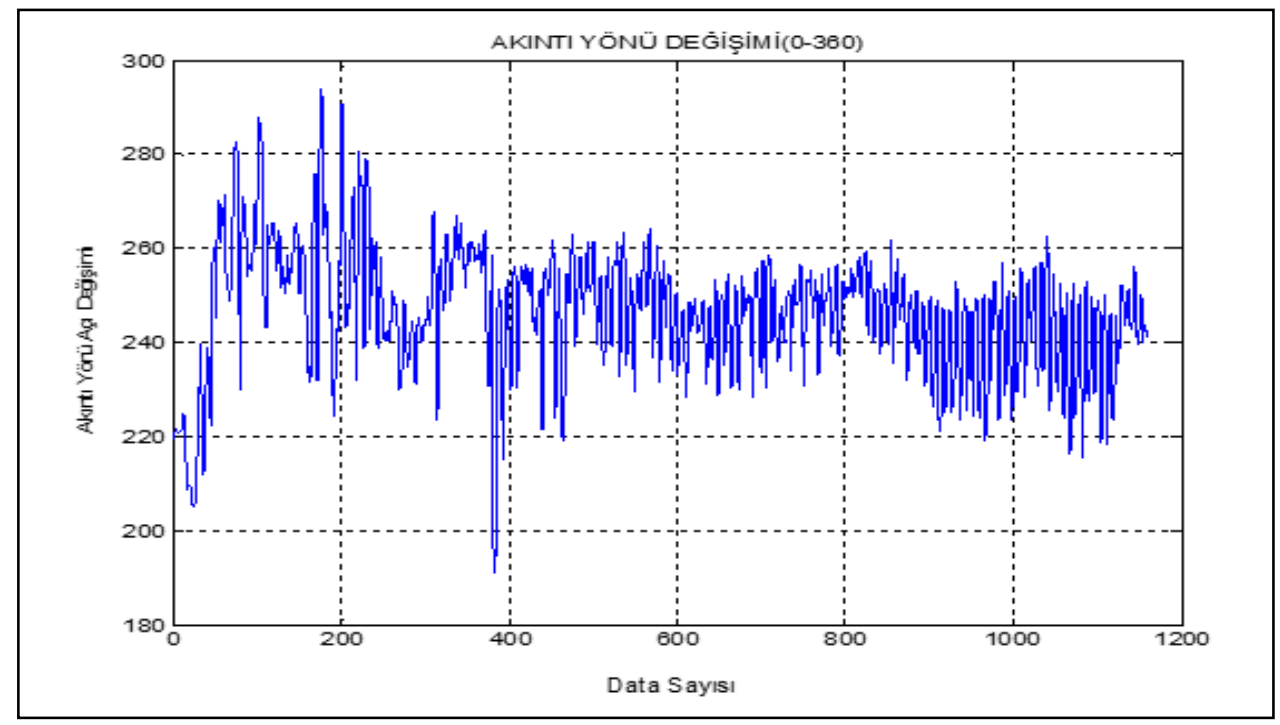

Şekil 11:

İkinci uygulama yeri (Tabyalar) akıntı yönü değişimi

Akıntı hızındaki değişim türbin devrini de etkilemektedir. Türbin Şekil 12'deki türbin devir değişim grafiğinde, ortalama $35 \mathrm{dev} / \mathrm{dk}$ ile dönmektedir. Ancak aynı hızlarda diğer bölgelerdeki türbin devir değişimi $200 \mathrm{dev} / \mathrm{dk}$ olduğu görülmüştür.

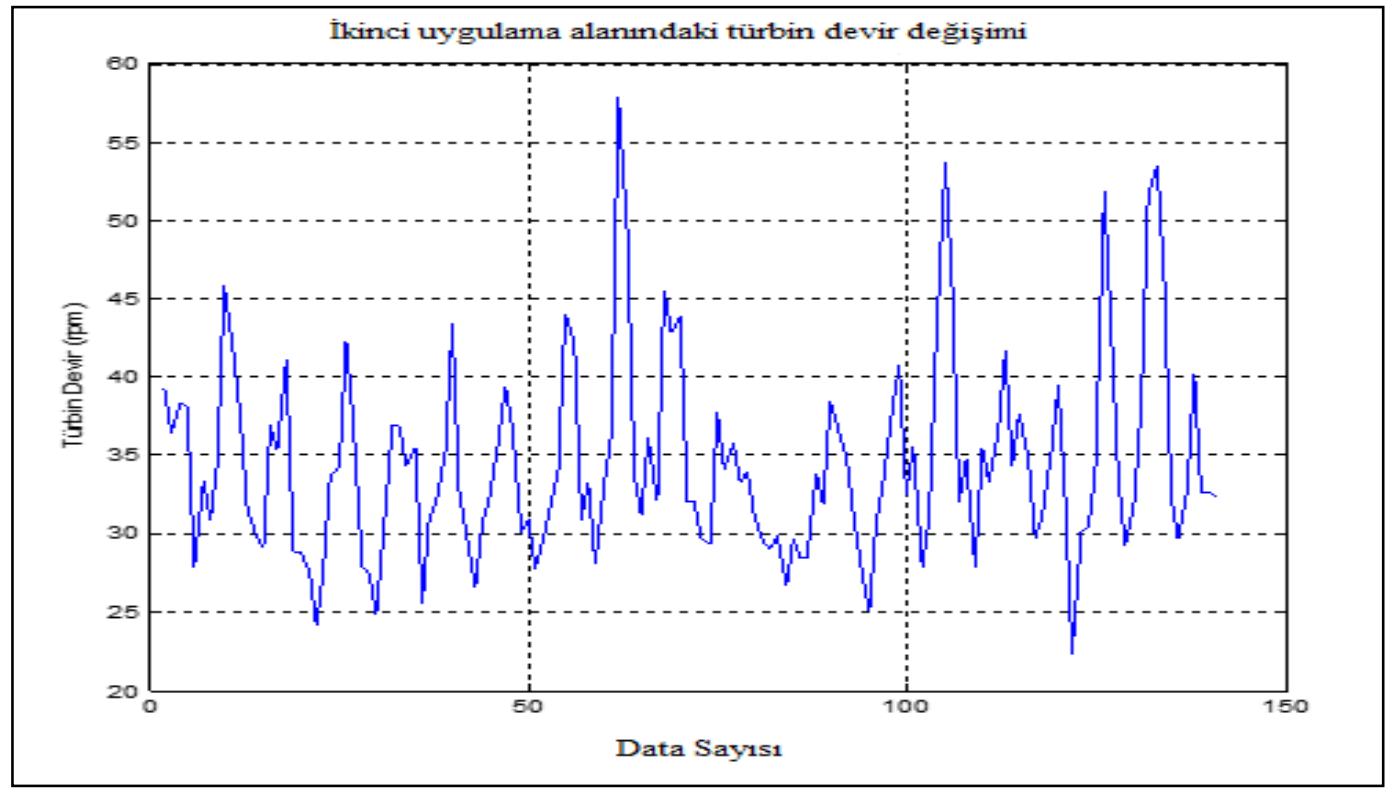

Şekil 12:

İkinci uygulama alanındaki türbin devir değişimi 


\section{3 Üçüncü Uygulama Yeri (Sarıçay ağzı)}

Üçüncü uygulama yeri olarak, $(40,145 ; 26,396)$ GPS koordinatlarına sahip olan Çanakkale Boğazında bulunan Sarıçay deresinin denize döküldüğü yerdir. Uygulama yapılan zamanda (01/10/2016) yağışların olmamasından dolayı Sarı Çay'dan denize akıntı yok denecek kadar düşüktür. Bu bölge boğazın daralan bölgelerinden biridir. Bu yüzden akıntı hızı yoğundur. Ancak bölgede Sarı çay' dan kaynaklanan toprak taşınmaları yüzünden derinlik azdır.

Üçüncü uygulama sahasında yapılan ölçümlerde Şekil 13'de verilen grafik akıntı yönü değişiminin farkı, ortalama $10^{\circ}$ olduğu gözlemlenmiştir. Burada deniz derinliği 3-5 m civarında olduğundan akıntı kalınlığı çok küçüktür. Deniz sığ olduğundan akıntı yüzeydeki rüzgârdan etkilenmektedir. Akıntıya karşı rüzgârın ters esmesi akıntı hızını durma noktasına getirmektedir. Rüzgâr akıntı yönüyle aynı yönde esmesi akıntı hızını arttırmaktadır. Ayrıca gel-git den dolayı deniz seviyesi aşırı düşmektedir. Bu durum akıntı kalınlığını düşürmektedir. Bunun yanında bu bölgede bulunan balıkçı iskelesine kayık geçişleri de sığ olan deniz akıntısını değiştirmektedir.

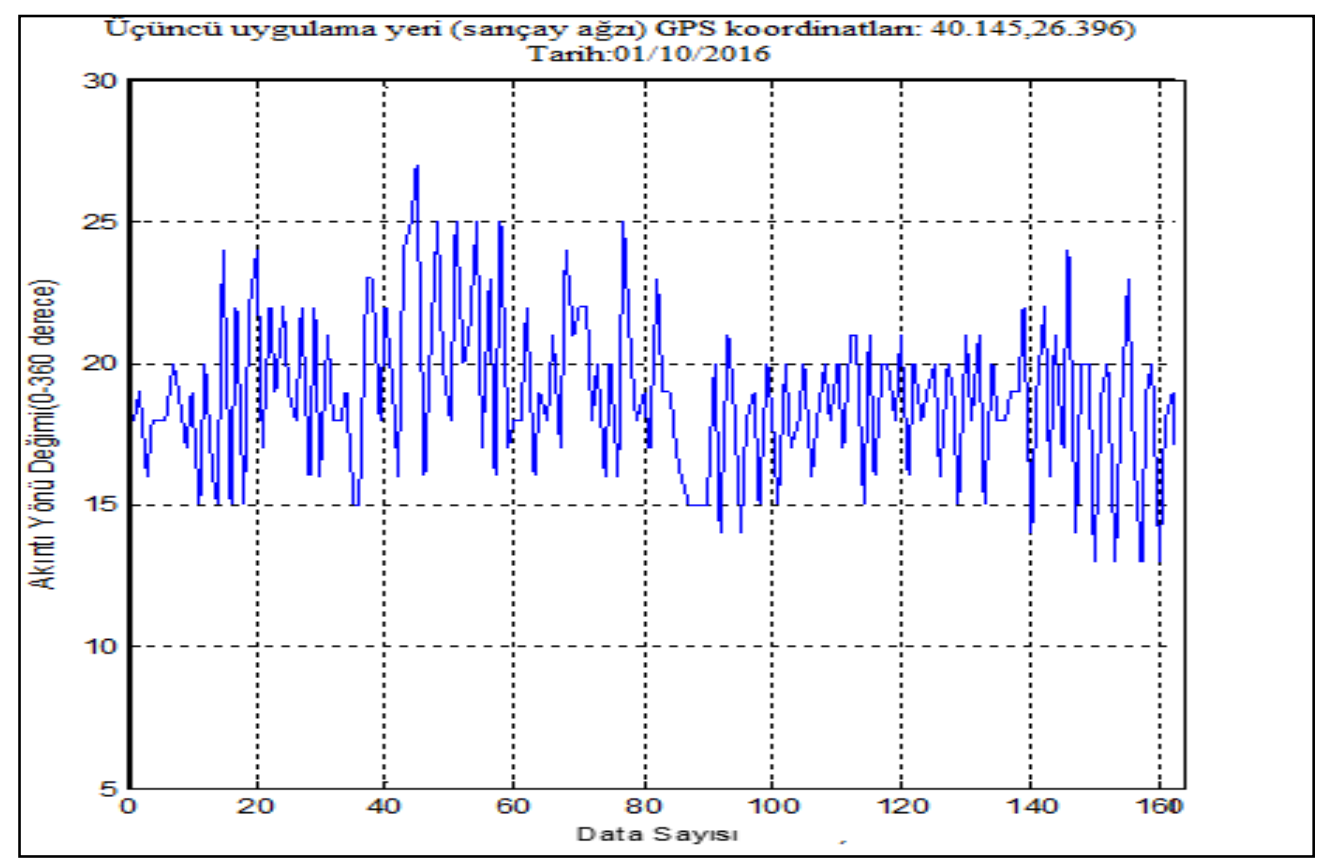

Şekil 13:

Sarıçay Ăgzı akıntı yön değişimi

\subsection{Boğaz Akıntı Hızı-Türbin Güç Değişimi}

Boğaz akıntısında akıntının fazla olduğu bölgelerde, farklı akıntı hızlarında türbin denemeleri yapılmıştır. Şekil 14'de verilen akıntı hızı - güç grafiğginde gösterildiği gibi türbin $0,4 \mathrm{~m} / \mathrm{s}$ akıntı hızında enerji üretmeye başlamıştır. Akıntının en fazla $2,48 \mathrm{~m} / \mathrm{s}$ ve en az $0,4 \mathrm{~m} / \mathrm{s}$ olduğu akıntı hızları arasında enerji üretim değerleri elde edilmiştir. Enerji üretim verimliliğine bakıldığında \%40,5 verimle çalıştığı bulunmuştur. 


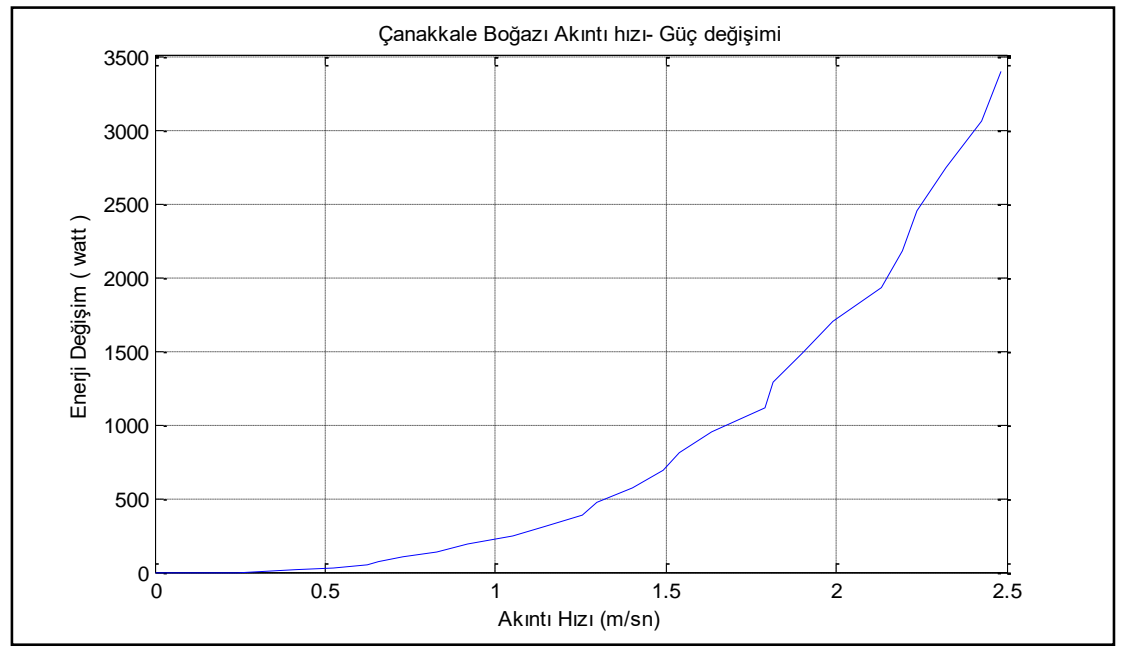

Şekil 14:

Çanakkale Boğazı tasarlanan türbin için yapılan uygulama sonuçlarındaki akıntı hız değişimine bağlı olarak elde edilen enerji çıkış dĕgeri

\section{SONUÇ}

Çanakkale boğazındaki akıntı zamanla değişen bir akıntıdır. Akıntı yüzeyde Ege Denizine doğru iken alttan bu akıntının yönü Marmara Denizine doğrudur. Yüzey akıntıları dış etmenlerden etkilenmektedir. Rüzgârın akıntı yönüne doğru ters esmesi yüzey akıntılarını ters yöne doğru iter bu durum akıntının tamamen durmasına bile sebep olur, rüzgâr akıntı yönünde esmesi ise arttırıcı etki yapar. Ancak bu durum yüzey akıntısı için belirli bir kalınlıkta etkilidir. Bahar aylarında Karadeniz'e gelen nehir suları arttıkça denizdeki su seviyesi yükselir. İstanbul Çanakkale ve Boğazlarında akıntıların artmasına neden olmaktadır.

$5 \mathrm{~kW}$ gücünde türbin ile yapılan elektrik üretim çalışmalarında boğazın farklı noktalarında çok kez deneme yapılmış ve bunun sonucunda $0-2,5 \mathrm{~m} / \mathrm{s}$ arasındaki akıntı hızlarında türbinin üretmiş olduğu elektrik miktarı bulunmuştur. Deniz akıntı türbinlerinde sızdırmazlık keçeleri özellikle deniz suyunda korozyona uğramakta ve kısa sürede bozulmaktadır. Su basıncı sızdırmazlık keçelerine baskı uygulamakta ve ana milin rahat dönmesini engellemektedir. Bunu engellemek için türbin içerisine basınçlı hava basılmıştır. Böylece türbin içerisindeki basınç ile su basıncı eşitlenmiş ve içeri suyun girmesi önlenmiştir. Bu şekilde türbin sızdırmazlık keçelerinin olumsuz etkilerinden kaçınılmıştır.

Türbin devir değişimi temiz enerji çıkışı için önemli olduğundan sabit dönmesi istenmektedir. Rüzgâr türbinlerinde olduğu gibi akıntı hızı da devamlı olarak küçükte olsa değişimler gösterdiğinden enerji çıkışı regüle devrelerle düzenlenmelidir. Bunun için bu çalışmada regüle devre olarak şebekeye paralel senkronizer devre elamanı kullanıldı. Bu şekilde temiz enerji sağlandı $(50 \mathrm{~Hz}, 380 \mathrm{~V})$.

Uygulama yapılan türbinde \%40,5 verime ulaşı1mıştır. Bahaj ve ark.(2007) laboratuarda, akıntı tünellerinde yaptıkları uygulama çalışmalarında \%46 verime ulaşmışlardır. Boğazdaki verimin bu oranda kalmasının sebebi akıntı yönünün sürekli değişim gösterdiğinden dolayıdır.

Çanakkale boğazındaki akıntı miktarı ve akıntı kalınlığına bakıldığında yapılan denemelerde görüldüğü gibi türbin kurulabilir. Kurulacak olan türbinler gemi geçişini etkilememesi için kıyı bölgelerine kurulmalıdır. Boğazdaki çift yönlü akıntı bulunduğundan dip akıntısına da türbin kurulması gemi geçişlerini engellemeyecektir. Yerleşim yerlerinin akıntı sahalarına yakın olduğundan dolayı ulusal şebekeye bağlanmadan kullanıma sunulabilir. Bu şekilde enerji iletim hatlarındaki iletim kayıplarından da kaçınılmış olur. 


\section{KAYNAKLAR}

1. Bahaj, A. S., Molland, A. F., Chaplin, J. R. \& Batten, W. M. J., 2007. Power and Thrust Measurements of Marine Current Turbines Under Various Hydrodynamic Flow Conditions in a Cavitation Tunnel and a Towing Tank, Renewable Energy 32, pp. 407-426. doi:10.1016/j.renene.2006.01.012

2. Bal S., Atlar M., Usar D.,2015. Performance prediction of horizontal axis marine current turbines Ocean Systems Engineering, Vol. 5, No. 2 (2015) 125-138 doi: 10.12989/ose.2015.5.2.125

3. Birjandi, A.H., Bibeau, E.L., Chartoorgoon, V., Kumar, A.., Power measurement of hydrokinetic turbines with free - surface and blockage effect. Ocean Engineering 2013; 69: 9-17. doi:10.1016/j.oceaneng.2013.05.023

4. Cui B., Zhiwei S., Yuliang Z., Yingzi J., Yonggang L, 2010. İnfluence of additional device on performance of the marine current türbine, Open Journel of Fluid Dynamics,2012, 2(04), 305-310. doi:10.4236/ojfd.2012.24A037

5. Çengel Y.A., Cimbala J.M., 2010. Akışkanlar mekaniği temelleri ve uygulamaları, Palme Yayınevi

6. D.M. Grogan, S.B. Leen, C.R Kennedy,C.M.Ó Brádaigh. Design of composite tidal turbines blades renevable energy 2013; 57:151-162. doi:10.1016/j.renene.2013.01.021

7. Hansen, M.O.L., 2015. Aerodynamics of Wind Turbines, 3rd edition, VA section 6, London-Sterling. doi: 10.4324/9781315769981

8. Jing Feng-mei, Wei-jia Ma, Liang Zhang, Shu-qi Wang, Xiao-hang Wang. Experimental study of hydrodynamic performance of full-scale horiontal axis tidal current türbine Available online at www.sciencedirect.com. Journal of hydrodynamics 2017,29(1):109-117. doi:10.1016/S1001-6058(16)60722-9

9. Malki, R., Williams, A.J., Croft, T.N., Togneri, M., Masters, I., A coupled blade elemnt momentum- computational fluid Dynamics model for evaluating tidal stream türbine performance. Aplied Mathematical Modelling 2013;37:3006-3020

10. Şenel M.C., Koç E., 2014 Yatay eksenli rüzgar türbinlerinin dinamik davranışı teorik bir model Dicle Ünv. Mühendislik fak. Dergsi cilt:5 sayı:1 69-80 
